Case Report

\title{
Coincidence of Large Adrenal Cyst and Prominent Hyporeninemic Hyperaldosteronism
}

\author{
Takaaki Sakaue, ${ }^{1}$ Yosuke Okuno $\mathbb{D}^{1},{ }^{1}$ Kosuke Mukai $\mathbb{D}^{1},{ }^{1}$ Shingo Fujita, ${ }^{1}$ Junji Kozawa, \\ Hitoshi Nishizawa, ${ }^{1}$ Taka-Aki Matsuoka, ${ }^{1}$ Hiromi Iwahashi, ${ }^{1,2}$ Maeda Norikazu, ${ }^{1,3}$ \\ Yuto Yamazaki, ${ }^{4}$ Hironobu Sasano, ${ }^{4}$ Michio Otsuki ${ }^{D},{ }^{1}$ and Iichiro Shimomura ${ }^{1}$ \\ ${ }^{1}$ Department of Metabolic Medicine, Osaka University Graduate School of Medicine, Osaka 565-0871, Japan \\ ${ }^{2}$ Department of Diabetes Care Medicine, Osaka University Graduate School of Medicine, Osaka 565-0871, Japan \\ ${ }^{3}$ Department of Metabolism and Atherosclerosis, Osaka University Graduate School of Medicine, Osaka 565-0871, Japan \\ ${ }^{4}$ Department of Pathology, Tohoku University Graduate School of Medicine, Sendai 980-8574, Japan
}

Correspondence should be addressed to Yosuke Okuno; wokuno@endmet.med.osaka-u.ac.jp and Michio Otsuki; otsuki@ endmet.med.osaka-u.ac.jp

Received 21 August 2020; Revised 28 January 2021; Accepted 11 February 2021; Published 20 February 2021

Academic Editor: Mihail A. Boyanov

Copyright (C) 2021 Takaaki Sakaue et al. This is an open access article distributed under the Creative Commons Attribution License, which permits unrestricted use, distribution, and reproduction in any medium, provided the original work is properly cited.

A 67-year-old Japanese woman who had end-stage renal disease was referred to our hospital for kidney transplantation. Abdominal CT revealed a large adrenal mass with inhomogeneity. She had a history of hospitalization for stroke and heart failure and exhibited prominent hyporeninemic hyperaldosteronism. Histological examination of the resected tumor with anti-CYP11B2 antibody indicated that she had a vascular endothelial cyst with primary aldosteronism (PA) due to multiple adrenocortical micronodules. This report implicates the pathological interaction between adrenal vascular cysts and PA-mediated vascular damage of the adrenal vein.

\section{Introduction}

Adrenal cysts are rare and form a heterogeneous group of lesions. Their incidence in autopsy has been reported to be $0.064-0.18 \%$ [1]. However, the frequency with which they are disclosed appears to be increasing because of improved radiological imaging techniques such as computed tomography (CT) and magnetic resonance imaging (MRI) [2]. Adrenal vascular endothelial cysts are one of the subtypes of adrenal cysts and associated with vascular damage [3]. Although aldosterone is directly involved in such vascular damage, coincidence of these two disorders was scarcely reported.

Etiologically, hypertension induced by excess aldosterone secretion features more prominent renal damage than essential hypertension [4]. When not treated appropriately, it eventually leads to end-stage renal disease (ESRD). Under these circumstances, endocrinological examinations are less valuable because of aberrant hormone metabolism and the risk of confirmation tests.
We herein present a case of combination of large adrenal endothelial cyst and prominent hyporeninemic hyperaldosteronism with ESRD where immunohistological examination was useful.

\section{Case Presentation}

A 67-year-old Japanese woman was referred to our hospital for renal replacement therapy and kidney transplantation. She had been diagnosed as hypertension at her late 20s, but blood pressure was poorly controlled despite treatment with antihypertensive drugs without an aldosterone antagonist. She had a history of hospitalization for stroke at 48 years old and heart failure at 53 years old. She was administrated with warfarin for atrial fibrillation. She was diagnosed as diabetes at 62 years old, but her glycemia was well-controlled with linagliptin. Her renal function had gradually impaired, most likely due to nephrosclerosis. In April 2018, her estimated glomerular filtration rate (eGFR) was $7 \mathrm{ml} / \mathrm{min} / 1.73 \mathrm{~m}^{2}$. 


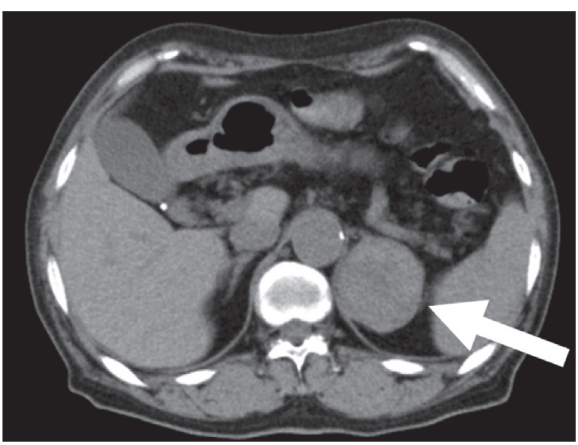

(a)

$\mathrm{T} 1$

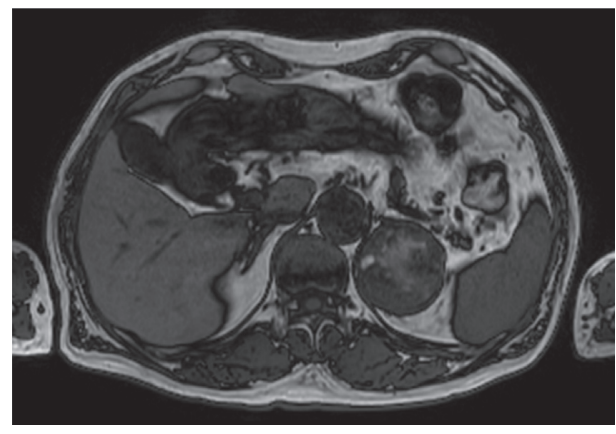

$\mathrm{T} 2$

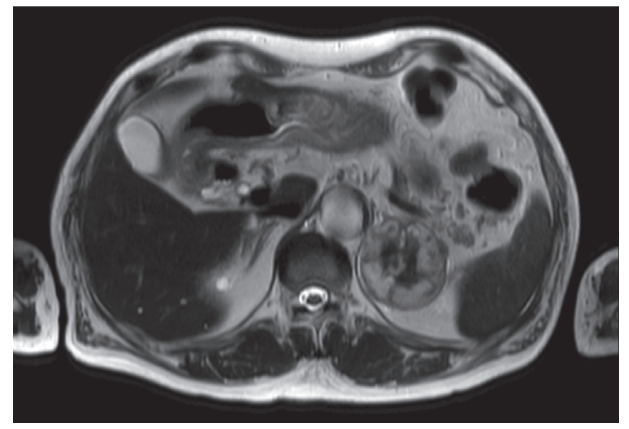

(b)

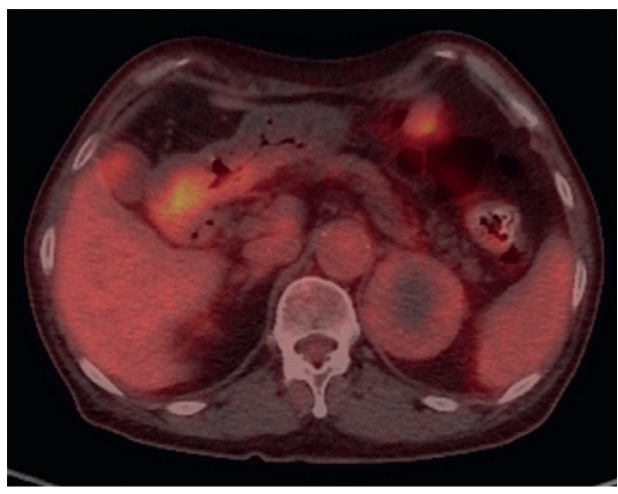

(c)

Figure 1: (a) Abdominal plain CT. Arrow: left adrenal mass (52 mm $\times 50 \mathrm{~mm}$ ). (b) T1-weighed (left) and T2-weighed (right) images of plain MRI. (c) PET-CT.

During the checkup for kidney transplantation, abdominal CT revealed a left adrenal mass, which was $5 \mathrm{~cm}$ in diameter with inhomogeneity of density and smooth borders (Figure 1(a)). She was admitted in August 2018 for endocrinological examination.

On admission, her blood pressure was $133 / 89 \mathrm{mmHg}$ with $5 \mathrm{mg}$ amlodipine, $60 \mathrm{mg}$ azosemide, and $0.625 \mathrm{mg}$ bisoprolol fumarate. She had no Cushingoid appearances. The plasma parameters are shown in Table 1. Her serum potassium level was at the lower limit of normal despite ESRD. She exhibited prominent hyporeninemic hyperaldosteronism. The plasma aldosterone concentration (PAC) was $514.9 \mathrm{pg} / \mathrm{ml}$, and plasma renin activity (PRA) was $<0.2 \mathrm{ng} / \mathrm{ml} / \mathrm{hr}$, but we could not perform saline infusion test nor captopril challenge test in afraid of deteriorating renal function and heart failure. The plasma ACTH level and serum cortisol level were within normal limits. The serum dehydroepiandrosterone-sulfate (DHEA-S) level was below the lower limit of normal. The midnight serum cortisol level was above $5 \mu \mathrm{g} / \mathrm{dl}$. Overnight $1 \mathrm{mg}$ dexamethasone suppression test could not suppress the serum cortisol level below $3 \mu \mathrm{g} / \mathrm{dl}$. Twenty-four-hour urinary excretion of cortisol was below the detection limit. Twenty-four-hour urinary excretion of catecholamines and their metabolites did not exceed normal limits. The serum testosterone and estradiol levels were within normal limits.

High-intensity in T1-weighted images (T1WI) and lowintensity in T2WI of abdominal MRI suggested bleeding in the adrenal mass (Figure 1(b)). ${ }^{123}$ I-metaiodobenzylguanidine (MIBG) was not uptaken into the adrenal mass (data not shown). On the positron emission tomography with fluorodeoxyglucose (FDG-PET), the mass 
TABle 1: Plasma parameters.

\begin{tabular}{|c|c|c|c|c|c|}
\hline \multicolumn{6}{|c|}{ Blood sample: on admission } \\
\hline WBC & $4.52 \times 10^{3}$ & $/ \mu \mathrm{L}$ & RBC & $4.41 \times 10^{6}$ & $/ \mu \mathrm{L}$ \\
\hline $\mathrm{Hb}$ & 11.9 & $\mathrm{~g} / \mathrm{dL}$ & Plt & $187 \times 10^{3}$ & $/ \mu \mathrm{L}$ \\
\hline Creatinine & 6.61 & $\mathrm{mg} / \mathrm{dL}$ & eGFR & 5.4 & $\mathrm{ml} / \mathrm{min} / 1.73 \mathrm{~m}^{2}$ \\
\hline $\mathrm{Na}$ & 144 & $\mathrm{mEq} / \mathrm{L}$ & K & 3.7 & $\mathrm{mEq} / \mathrm{L}$ \\
\hline PRA & $\leqq 0.2$ & $\mathrm{ng} / \mathrm{mL} / \mathrm{hr}$ & PAC & 514.9 & $\mathrm{pg} / \mathrm{mL}$ \\
\hline ACTH & 25 & $\mathrm{pg} / \mathrm{mL}$ & Cortisol & 14.5 & $\mu \mathrm{g} / \mathrm{dL}$ \\
\hline DHEA-S & 25 & $\mu \mathrm{g} / \mathrm{dL}$ & Estradiol & $<14.0$ & $\mathrm{ng} / \mathrm{mL}$ \\
\hline Testosterone & 0.24 & $\mathrm{ng} / \mathrm{mL}$ & HbA1c & 5.6 & $\%$ \\
\hline \multicolumn{6}{|l|}{ Urine sample } \\
\hline U-adrenaline & 1.08 & $\mu \mathrm{g} / \mathrm{day}$ & U-VMA & 2.16 & $\mathrm{mg} /$ day \\
\hline U-noradrenaline & 55.26 & $\mu \mathrm{g} /$ day & U-metanephrine & 0.036 & $\mathrm{mg} / \mathrm{day}$ \\
\hline U-dopamine & 100.8 & $\mu \mathrm{g} / \mathrm{day}$ & U-normetanephrine & 0.126 & $\mathrm{mg} /$ day \\
\hline U-cortisol & \multicolumn{5}{|c|}{ Below the detection limit } \\
\hline \multicolumn{6}{|c|}{ Diurnal profile of ACTH and cortisol } \\
\hline Time & $6: 00$ & $23: 00$ & & & \\
\hline $\mathrm{ACTH}(\mathrm{pg} / \mathrm{mL})$ & 23 & 7 & & & \\
\hline Cortisol $(\mu \mathrm{g} / \mathrm{dL})$ & 16.4 & 6.9 & & & \\
\hline \multicolumn{6}{|c|}{ Low-dose dexamethasone suppression test } \\
\hline \multicolumn{6}{|c|}{ After $1 \mathrm{mg}$} \\
\hline ACTH (pg/mL) & 2 & & & & \\
\hline Cortisol $(\mu \mathrm{g} / \mathrm{dL})$ & 4.5 & & & & \\
\hline \multicolumn{6}{|c|}{ Blood sample: one month after surgery } \\
\hline $\mathrm{K}$ & 4.4 & $\mathrm{mEq} / \mathrm{L}$ & eGFR & 5.1 & $\mathrm{ml} / \mathrm{min} / 1.73 \mathrm{~m}^{2}$ \\
\hline PRA & $\leqq 0.2$ & $\mathrm{ng} / \mathrm{mL} / \mathrm{hr}$ & PAC & 533.6 & $\mathrm{pg} / \mathrm{mL}$ \\
\hline ACTH & 31 & $\mathrm{pg} / \mathrm{mL}$ & Cortisol & 13.5 & $\mu \mathrm{g} / \mathrm{dL}$ \\
\hline DHEA-S & 3.8 & $\mu \mathrm{g} / \mathrm{dL}$ & & & \\
\hline
\end{tabular}

had activity less than that of the liver (Figure 1(c)). Considering the size above $4 \mathrm{~cm}$ and bleeding inside, the tumor was laparoscopically resected for suspected malignancy. After surgery, PAC, PRA, plasma ACTH, and serum cortisol remained almost unchanged, while blood pressure was decreased to $108 / 70 \mathrm{mmHg}$ and serum potassium level was increased to $4.4 \mathrm{mEq} / \mathrm{L}$ (Table 1 ).

On gross inspection, the tumor exhibited multiple nodular solid lesions with prominent bleeding (Figure 2). The blood tumor was an adrenal vascular endothelial cyst surrounded by CD31-positive/PDPN-negative endothelial lining and papillary hyperplasia (Figure 3(a)). There was no arteriovenous malformation. As a possible source of hyperaldosteronism, CYP11B2-positive multiple adrenocortical micronodules ( $\mathrm{MN}$ ) surrounded by hyperplastic zona glomerulosa without diffuse overexpression of CYP11B2 were identified (Figure 3(b)). The expression of dehydroepiandrosterone sulfotransferase (DHEA-ST) in zona reticularis was normal (Figure 3(c)).

\section{Discussion}

In this paper, we report the unique case of prominent hyporeninemic hyperaldosteronism with a large vascular endothelial cyst. The coincidence of hyporeninemic hyperaldosteronism and adrenal cyst was reported only in one case report, where primary aldosteronism (PA) by adrenal adenoma was combined with ipsilateral pseudocyst [5].

The cause of adrenal vascular endothelial cysts and pseudocysts is not clear, but they are considered to originate

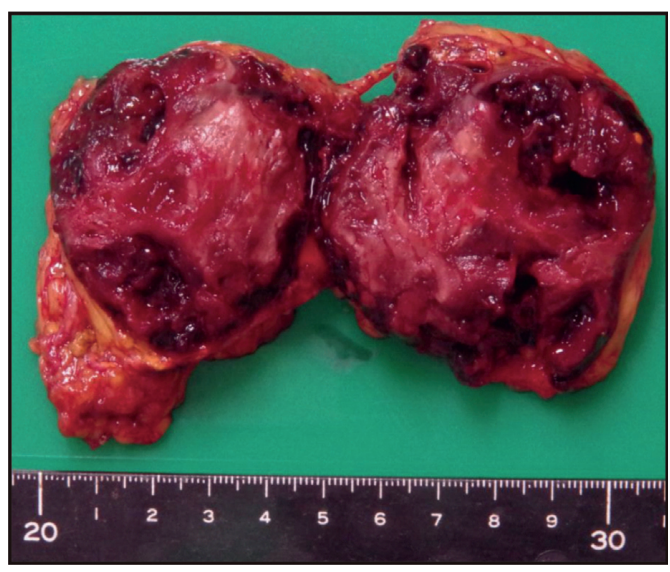

Figure 2: Gross inspection of the resected tumor.

from prior hemorrhage from pre-existing vascular hamartoma or adrenal vein $[3,6]$. As aldosterone is known to be directly involved in vascular damage [7] and hemodynamics within the tissue [8], it might attribute to such adrenal hemorrhages. For example, intra-adrenal veins are considered to be uniquely fragile in patients with $\mathrm{PA}$, from the fact that extremely high rate of intra-adrenal hemorrhage was experienced specifically in adrenal venography of PA [9]. As a possible mechanism, mineralocorticoid receptor was expressed in vascular smooth muscle cells (VSMC) [10] and direct mineralocorticoid effect on vascular tone and contractility has been suggested [11-13]. Aldosterone also stimulates fibroblast-mediated fibrosis in a vascular matrix 
H-E

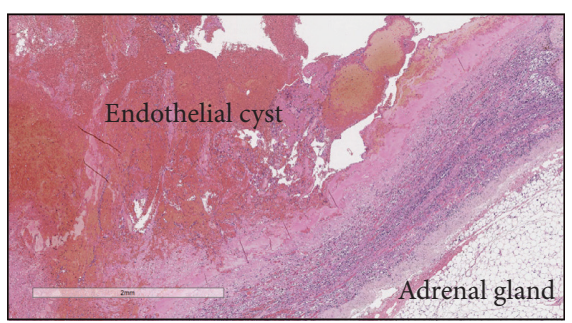

CD31

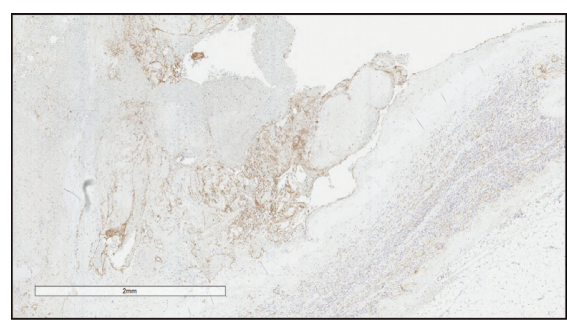

PDPN

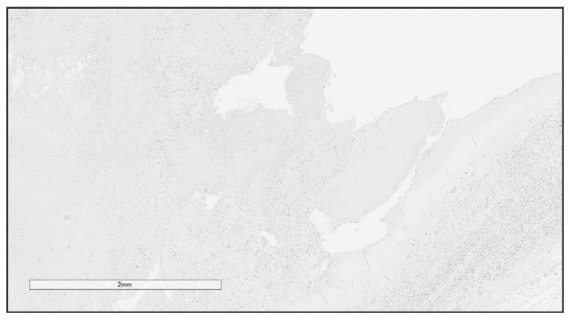

(a)

\section{CYP11B2 (loupe)}

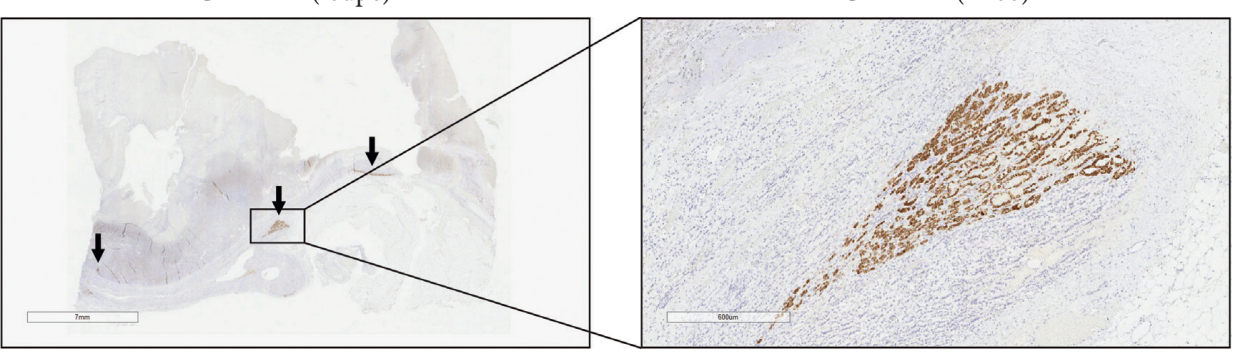

(b)

DHEA-ST (loupe)

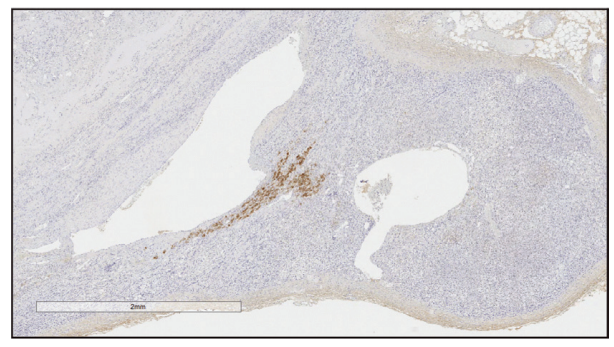

(c)

FIGURe 3: (a) H-E staining (H-E) immunostaining with anti-CD31 antibody (CD31) or anti-PDPN (D2-40) antibody (PDPN) of the resected tumor (magnification: x200). (b) Immunostaining of the resected tumor with anti-CD11B2 antibody. Left: loupe, right: x400 magnification. Arrow: CYP11B2-positive regions. (c) Immunostaining with anti-DHEA-ST antibody of the adjacent adrenal gland (magnification: x20).

[14-16]. PA not only increases intravascular volume in the whole body [17] but also decreases local vascular resistance, at least in the kidney [8], which may increase the flow volume in the tissue. Analogically, PA might also increase the flow volume of the adrenal vein and make it prone to hemorrhage. In this case, hemorrhagic diathesis by warfarin would be attributed to adrenal hemorrhages. ESRD may also be attributed to vascular cysts, as congestion or hemorrhage was frequently observed in the adrenal of patients with ESRD in an autopsy analysis [18].

In patients with ESRD, it is difficult to evaluate autonomous aldosterone secretion. The aldosterone-to-renin ratio
(ARR) is elevated in chronic renal disease [19], and saline infusion test or captopril challenge test need caution as they might exaggerate the renal impairment. In this case, we could not endocrinologically diagnose but strongly suspected PA from poorly controlled hypertension, multiple PA-related complications, and low serum potassium despite ESRD, together with prominent hyporeninemic hyperaldosteronism. Identification of CYP11B2-positive lesions surrounded by hyperplastic zona glomerulosa further supported this speculation [20]. In this case, as serum potassium level and blood pressure were improved after surgery, significant amount of aldosterone may be produced by the 
same side of adrenal. Although hyporeninemic hyperaldosteronism still existed after removal of the left adrenal containing CYP11B-positive lesions, it was not surprising as the majority of $\mathrm{MN}$ is bilateral [21]. If this case was PA, aldosterone concentration would be much higher in the adrenal vein than in the blood, which further accelerated the formation of adrenal endothelial cyst.

It is also challenging to evaluate autonomous cortisol secretion in ESRD. The morning plasma cortisol is higher, and $1 \mathrm{mg}$ dexamethasone fails to suppress plasma total cortisol in patients with chronic renal failure [22]. The serum DHEA-S level is decreased in hemodialysis patients [23]. In this case, the possibility of coexisting subclinical Cushing syndrome could not be ruled out by dexamethasone suppression test or midnight serum cortisol, but was unlikely from the normal expression of DHEA-ST in zona reticularis. We assumed that the patient was in the pseudo-Cushing state caused by ESRD.

This case implicated the pathological interaction between adrenal vascular cyst and aldosterone-mediated vascular damage or hemodynamics of adrenal vein and showed the usefulness of immunohistochemistry to understand the endocrinological state in ESRD.

$\mathrm{LH}$ :luteinizing hormone, FSH: follicle-stimulating hormone, PRL:prolactin, ACTH: adrenocorticotropic hormone, DHEA-S : dehydroepiandrosterone-sulfate, TSH : thyroid stimulating hormone, FT3: free triiodothyronine, FT4: free thyroxine, PRA:plasma renin activity, PAC: plasma aldosterone concentration, and U-VMA: urinary vanillyl mandelic acid.

\section{Disclosure}

This research was performed as part of the employment of the authors by Iichiro Shimomura.

\section{Conflicts of Interest}

The authors declare no conflicts of interest.

\section{Authors' Contributions}

Iichiro Shimomura was involved in manuscript editing.

\section{References}

[1] L. M. Neri and F. C. Nance, "Management of adrenal cysts," The American Surgeon, vol. 65, no. 2, pp. 151-163, 1999.

[2] J. Fan, J. Tang, J. Fang et al., "Ultrasound imaging in the diagnosis of benign and suspicious adrenal lesions," Medical Science Monitor : International Medical Journal of Experimental and Clinical Research, vol. 20, pp. 2132-2141, 2014.

[3] E. Carvounis, A. Marinis, N. Arkadopoulos, T. Theodosopoulos, and V. Smyrniotis, "Vascular adrenal cysts: a brief review of the literature," Archives of Pathology \& Laboratory Medicine, vol. 130, no. 11, pp. 1722-1724, 2006.

[4] G. P. Rossi, G. Bernini, G. Desideri et al., "Renal damage in primary aldosteronism," Hypertension, vol. 48, no. 2, pp. 232-238, 2006.
[5] M. Watanabe, H. Matsuura, T. Oshima et al., "Primary aldosteronism with ipsilateral adrenal cyst: report of a case," Endocrine Journal, vol. 40, no. 5, pp. 619-624, 1993.

[6] A. Kawashima, C. M. Sandler, R. D. Ernst et al., "Imaging of nontraumatic hemorrhage of the adrenal gland," Radiographics, vol. 19, no. 4, pp. 949-963, 1999.

[7] D. Duprez, M. De Buyzere, E. R. Rietzschel, and D. L. Clement, "Aldosterone and vascular damage," Current Hypertension Reports, vol. 2, no. 3, pp. 327-334, 2000.

[8] L. A. Sechi, A. Di Fabio, M. Bazzocchi, A. Uzzau, and C. Catena, "Intrarenal hemodynamics in primary aldosteronism before and after treatment," The Journal of Clinical Endocrinology \& Metabolism, vol. 94, no. 4, pp. 1191-1197, 2009.

[9] J. J. Bookstein, J. Conn, and S. R. Reuter, "Intra-adrenal hemorrhage as a complication of adrenal venography in primary aldosteronism," Radiology, vol. 90, no. 4, pp. 778-779, 1968.

[10] Y. Takeda, I. Miyamori, S. Inaba et al., "Vascular aldosterone in genetically hypertensive rats," Hypertension, vol. 29, no. 1, pp. 45-48, 1997.

[11] L. Tobian and P. D. Redleaf, "Effect of hypertension on arterial wall electrolytes during desoxycorticosterone administration," American Journal of Physiology-Legacy Content, vol. 189 , no. 3, pp. 451-454, 1957.

[12] T. R. Hansen and D. F. Bohr, "Hypertension, transmural pressure, and vascular smooth muscle response in rats," Circulation Research, vol. 36, no. 5, pp. 590-598, 1975.

[13] L. Kornel, "The role of vascular steroid receptors in the control of vascular contractility and peripheral vascular resistance," The Journal of Steroid Biochemistry and Molecular Biology, vol. 45, no. 1-3, pp. 195-203, 1993.

[14] A. Benetos, P. Lacolley, and M. E. Safar, "Prevention of aortic fibrosis by spironolactone in spontaneously hypertensive rats," Arteriosclerosis, Thrombosis, and Vascular Biology, vol. 17, no. 6, pp. 1152-1156, 1997.

[15] R. MacFadyen, C. S. Barr, and A. D. Struthers, “Aldosterone blockade reduces vascular collagen turnover, improves heart rate variability and reduces early morning rise in heart rate in heart failure patients," Cardiovascular Research, vol. 35, no. 1, pp. 30-34, 1997.

[16] Y. Sun, F. J. Ramires, and K. T. Weber, "Fibrosis of atria and great vessels in response to angiotensin II or aldosterone infusion," Cardiovascular Research, vol. 35, no. 1, pp. 138-147, 1997.

[17] R. C. Tarazi, M. M. Ibrahim, E. L. Bravo, and H. P. Dustan, "Hemodynamic characteristics of primary aldosteronism," New England Journal of Medicine, vol. 289, no. 25, pp. 1330-1335, 1973.

[18] A. N. Elias, N. D. Vaziri, S. Farooqui, D. C. Martin, and M. K. Mirahmadi, "Pathology of endocrine organs in chronic renal failure-an autopsy analysis of 66 patients," The International Journal of Artificial Organs, vol. 7, no. 5, pp. 251-256, 1984.

[19] R. J. Hené, P. Boer, H. A. Koomans, and E. J. Dorhout Mees, "Plasma aldosterone concentrations in chronic renal disease," Kidney International, vol. 21, no. 1, pp. 98-101, 1982.

[20] S. Boulkroun, B. Samson-Couterie, J.-F. G. Dzib et al., "Adrenal cortex remodeling and functional zona glomerulosa hyperplasia in primary aldosteronism," Hypertension, vol. 56, no. 5, pp. 885-892, 2010.

[21] Y. Yamazaki, Y. Nakamura, K Omata et al., "Histopathological classification of cross-sectional image-negative hyperaldosteronism," The Journal of Clinical Endocrinology and Metabolism, vol. 102, no. 4, pp. 1182-1192, 2017. 
[22] E. Z. Wallace, P. Rosman, N. Toshav, A. Sacerdote, and A. Balthazar, "Pituitary-adrenocortical function in chronic renal failure: studies of episodic secretion of cortisol and dexamethasone suppressibility," The Journal of Clinical Endocrinology \& Metabolism, vol. 50, no. 1, pp. 46-51, 1980.

[23] R. Kakiya, T. Shoji, T. Hayashi et al., "Decreased serum adrenal androgen dehydroepiandrosterone sulfate and mortality in hemodialysis patients," Nephrology Dialysis Transplantation, vol. 27, no. 10, pp. 3915-3922, 2012. 